\title{
Design and Development of College Student Worksheets for Simulation of Electromagnetic Waves
}

\author{
Marlinda Siahaan $^{\text {a) }}$, Betty Zelda Siahaan \\ Faculty of IT, Universitas Advent Indonesia, Jl. Karyawangi No. 12. Parongpong, Bandung Barat, \\ 40559, Indonesia \\ $\bowtie:{ }^{a)}$ msiahaan@unai.edu
}

\begin{abstract}
Many studies show that student worksheets can be suitable teaching materials to achieve learning objectives, whether at school or college. Also, college student worksheets can make it easier for students to learn computing-based lessons. This study aims to design and develop worksheets and integrate them with computational thinking (CT) skills in computer programming courses. The material intended to be used as a worksheet is how to simulate electromagnetic waves (EM). This worksheet is also designed with group activities and is expected to improve collaboration skills between college students. This study uses research and development (R\&D) methods with the 4D model approach but does not do the fourth stage, dissemination. The worksheet developed has six main elements: (1) titles, (2) study guides, (3) essential competencies, (4) subject matter or supporting information, (5) tasks or work steps, and (6) student assessments. The resulting worksheet products have also been assessed by peers and declared worthy as teaching materials. In addition, the resulting worksheet has shown the steps in CT, namely, abstraction, algorithm, and generalization.
\end{abstract}

Keywords: college student worksheet, computational thinking, electromagnetic waves

\section{INTRODUCTION}

Physics is a science that discusses physical phenomena that exist in nature (Frigerio et al. 2021) with a comprehensive scope. In studying physical sensations, we can use a theoretical or experimental approach. The general workflow in physics (even science in general) is that we first observe a physical phenomenon around us and then develop a set of theories to explain the phenomenon (Jylkkä \& Railo 2019). Furthermore, experiments were conducted to test whether the approach that scientists had built was valid and consistent.

Along with the development of science and technology, computational methods are used as a new approach in studying physical phenomena (Plevris \& Tsiatas 2018). By combining computational methods with the laws of Physics, we can build various simulations to describe a physical phenomenon. A simulation is also an option to test a physics theory. Still, it cannot carry out good experiments, either because of our inability to build the necessary experimental equipment or the investigation really cannot be carried out. For example, when someone wants to study an electromagnetic field, of course, the experiment will be challenging. The more straightforward thing is to make computational simulations by setting all the parameters of the physical data that are close to reality and applying the related laws of physics. While some of the most exciting challenges are applying computational methods to multi-physical problems, such as thermo-mechanics, electromagnetic-mechanical, thermochemical, fluid-structure interactions, biomechanical engineering, etc (Plevris \& Tsiatas 2018). 
Electromagnetic wave radiation is described by electric field vectors and magnetic field vectors. Maxwell's equations determine the propagation of the two field vectors (Griffits 1999). The differential form of Ampere's law extension describes the formation of an induced magnetic field due to the flow of charge. The differential form of Faraday's law of induction represents the induced electric field due to changes in the magnetic flux with time. The differential form of Coulomb's law, which describes the relationship between the distribution of electric fields and charge, shows that a single magnetic pole has never been observed. This electromagnetic fields simulation uses the Fast Fourier Transform (FFT) method. FFT is an algorithm that is refined from Fourier analysis (Trinh-Xuan et al. 2011). This transformation can be used to calculate the frequency of a signal.

When teaching students about electromagnetic fields, lecturers can also use simulations. Using simulation is closely related to computational thinking ability. So, lecturers need to prepare learning activities and worksheets characterized by computational thinking (CT). CT takes an approach to solving problems, designing systems, and understanding human behavior that refers to the basic concepts of computing. CT can be applied in different subjects at different grade levels, which brings both challenges and opportunities (Tang et al. 2020). Lecturers must design systematic CT learning activities starting from how to teach CT, assess CT, and use technology to teach CT concepts.

Simulation is used to collect data or observe phenomena. When using the simulation, there must be clear instructions on how to use the simulation so that learning objectives are achieved. In addition, the user manual is essential to prevent errors in using the simulation. Misuse of simulation will affect the level of accuracy of the data taken. Educators quickly develop teaching materials as instructions for using simulations are in printed form. One of them is teaching materials in the form of student worksheets. Student worksheets are resources and media to help students learn focused (Rufaida et al. 2013) and procedurally (Gurl et al. 2016). Student worksheets contain a list of materials, concepts, and understandings that students will build through the problems given.

Therefore, the writer will develop a worksheet to facilitate college students using simulations in this study. The simulation is a simulation of Electromagnetic Waves Using Fourier Transforms. The produced worksheet has at least six main elements: (1) title, (2) study guide, (3) essential competencies, (4) subject matter or supporting information, (5) tasks or work steps, and (6) assessment of the student.

\section{METHODS}

This research produces a product in worksheets integrated with CT to explore the simulation of electromagnetic fields in computer programming courses. This research uses the research and development $(R \& D)$ method with the 4D Thiagarajan model. Thiagarajan's 4D model consists of 4 stages, but this research only adapts three steps: Define, Design, and Develop, without Disseminate. The writer chose the 4D model because this research only aims to design and develop worksheets.

Educational researchers use research and development $(R \& D)$ a lot to create student worksheets, for example, to maximize the results of learning and motivation in economic mathematics learning (Nasrullah et al. 2018), to student reflections on learning with challenging tasks (Russo \& Hopkins 2017), and validity science process skills worksheet through inquiry learning models (Yulkifi et al., 2019). In terms of research and development studies, many commonly used models, for example, ADDIE (Muliyati et al. 2021), Borg \& Gall (Khasanah et al. 2017), and Dick Carey (Bakri et al. 2019). Of the many models, the 4D model is the most relevant in applying this research.

In the first stage, namely define, the researcher establishes and defines the learning requirements. Given that these worksheets must be integrated with CT, the writers will directly insert the components of the worksheets with materials that can improve students' CT skills. In the second stage, the design stage aims to design learning devices. Appendix 1 shows the CT Skills Model that can be applied in schools (Atmatzidou \& Demetriadis 2016). While Appendix 2 is CT Skills and relevant clues to trigger students' self-reflection. So that the writer will develop the evaluation of learning in the worksheets according to Appendix 2. The third stage, the development stage, is the stage to produce development products, such as conducting expert appraisals followed by revisions. 


\section{RESULTS AND DISCUSSION}

\section{Simulation}

The simulation used uses python programming. In visualizing electromagnetic waves, the author uses the Matplotlib library. Matplotlib is the most popular library or package in the Python language for visualizing data, such as plotting graphs for one or more axes. Each axis has a horizontal (x) axis and a vertical (y) axis. Print out coding and simulation are presented in FIGURE 1 and FIGURE 2.

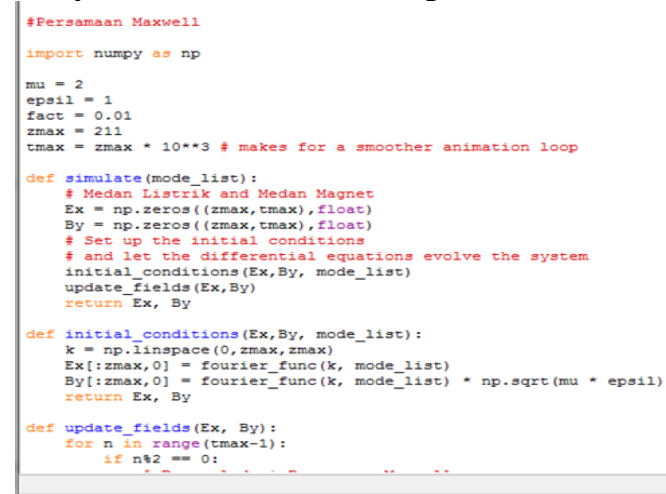

(1)

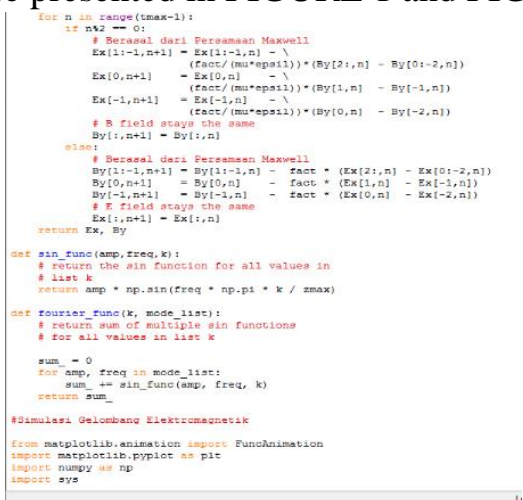

(2)

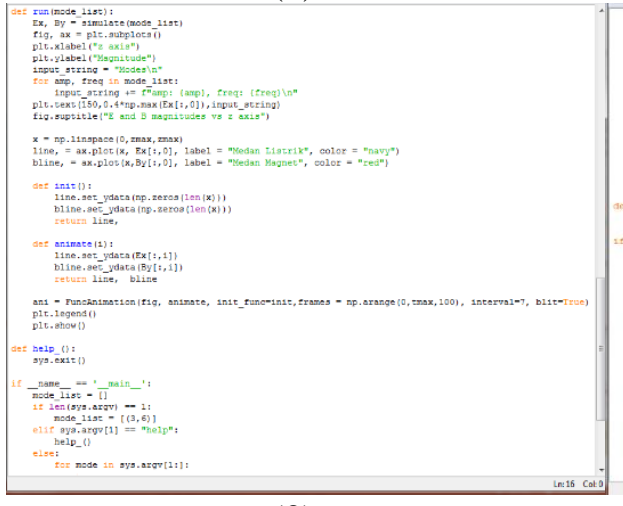

(3)

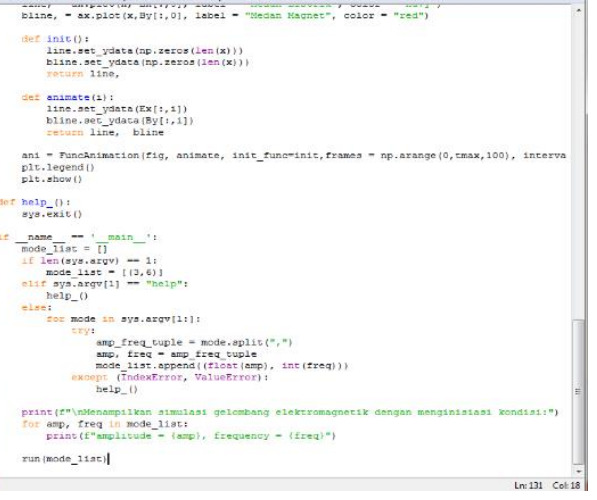

(4)

FIGURE 1. print screen coding using python (1) initiation for Maxwell equation, (2) initiation for electromagnetic wave simulation, (3) plotting axis using Matplotlib, and (4) code for printing out the plotting

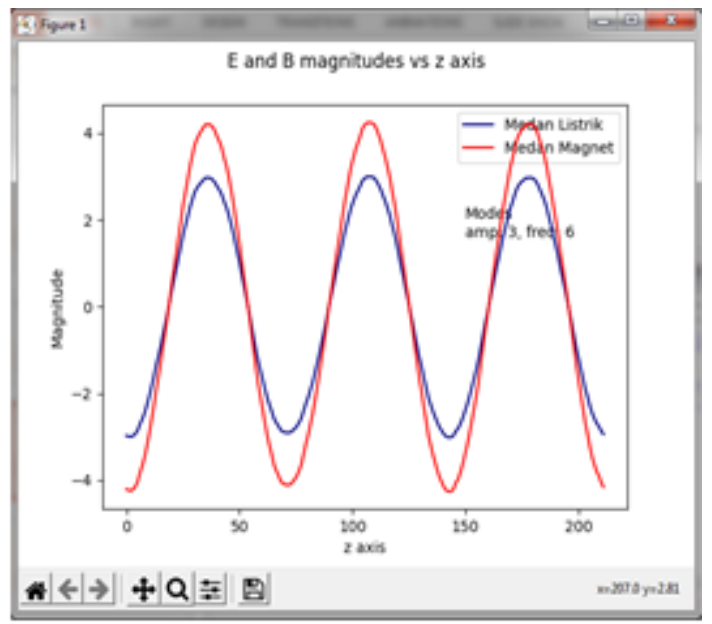

FIGURE 2. print screen simulation plotting graphs based on the coding source, blue color for electric field and red color for magnetic field 


\section{College Students Worksheet}

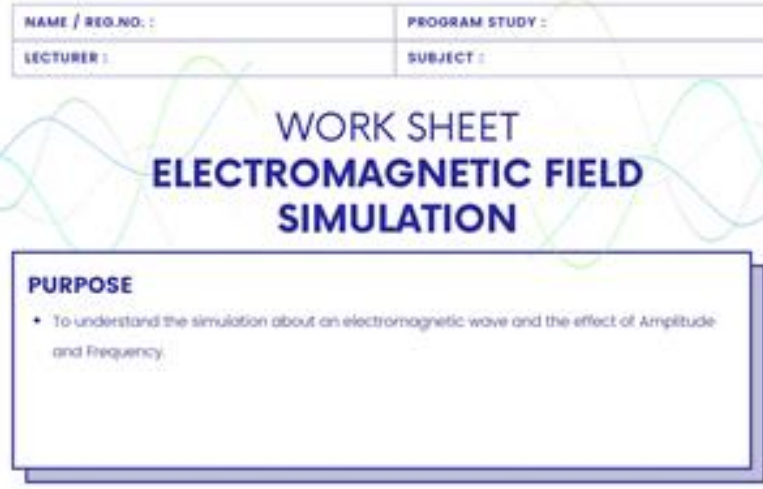

FIGURE 3. The first page of worksheet (cover)

The worksheet developed by the author is integrated with CT. CT has three dimensions (Lin et al. 2020), and each dimension is added to each step of the worksheet. The worksheet steps are shown in FIGURE 3, 4, 5, 6, and 7. As for student learning outcomes, it is crucial to monitor and support a good teaching and learning process. Learning outcomes are beneficial as practical tools in teaching and learning activities and designing learning programs (Hussey \& Smith 2010). Learning outcomes with the CT Skills model applied in the study can be seen in TABLE 1. TABLE 1 format following the results of Muliyati's research (2021).

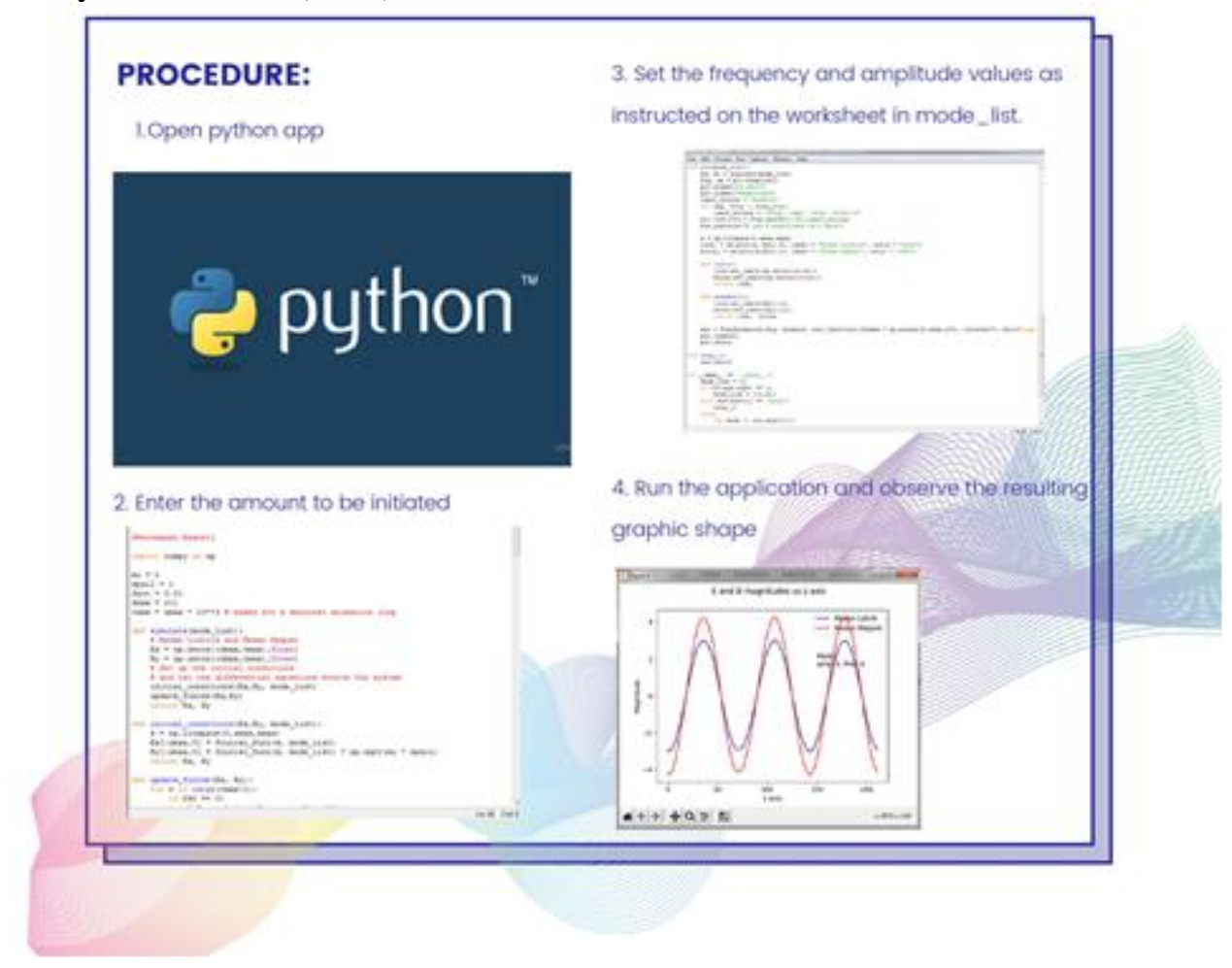

FIGURE 4. The procedure for using the simulation

The cover (FIGURE 3), the first page of the worksheet, provides the learning objectives. It is important to identify goals that students must achieve in class to stimulate and arouse attention (Waiyakoon et al. 2015). The procedure in the LKS stage is needed to invite students to understand what to do (FIGURE 4). Some lecturers give these stages orally, though, to support independent study, worksheets can be added with procedures (Bakri et al. 2020). 
TABLE 1. Learning outcomes with the CT Skills model applied in the study

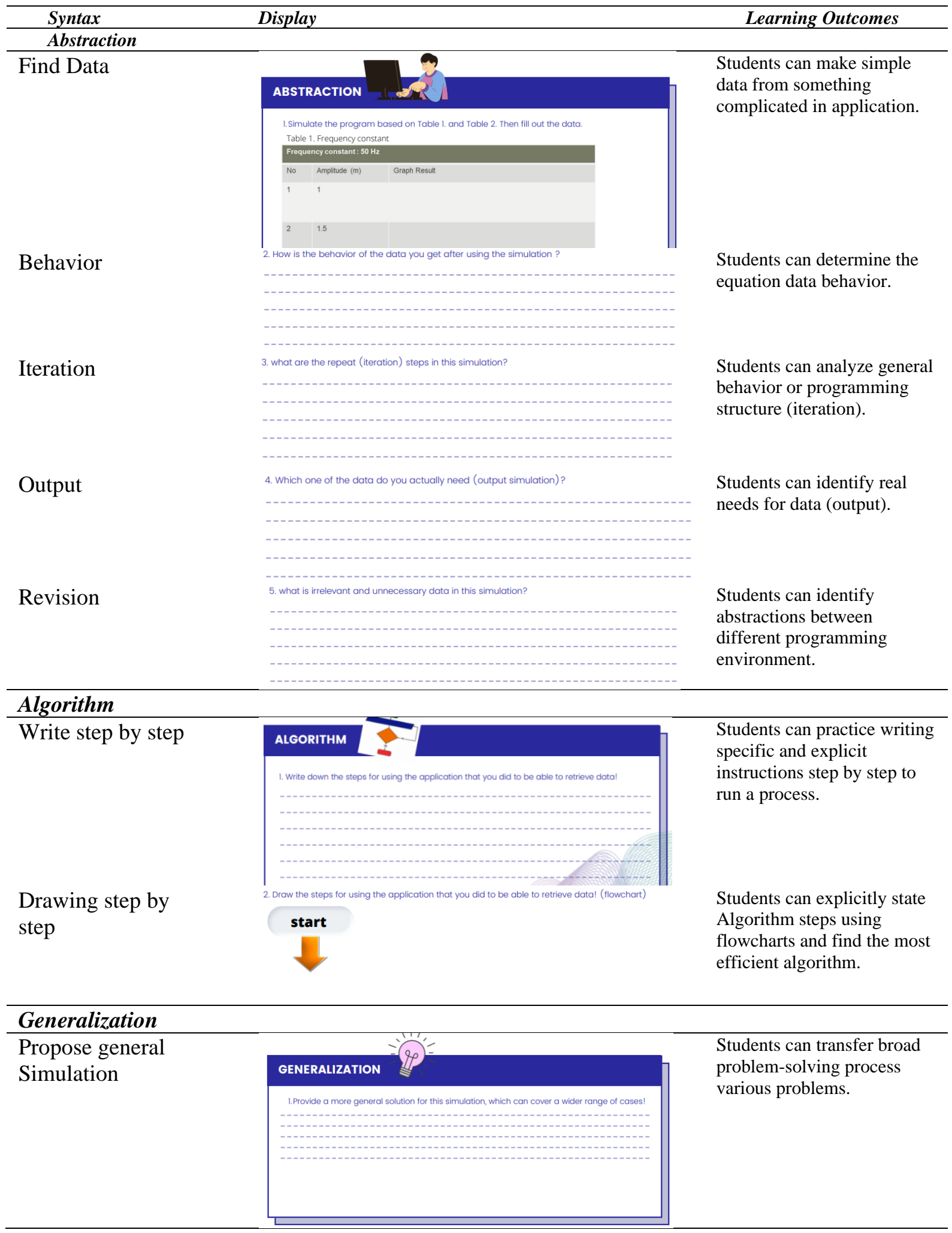




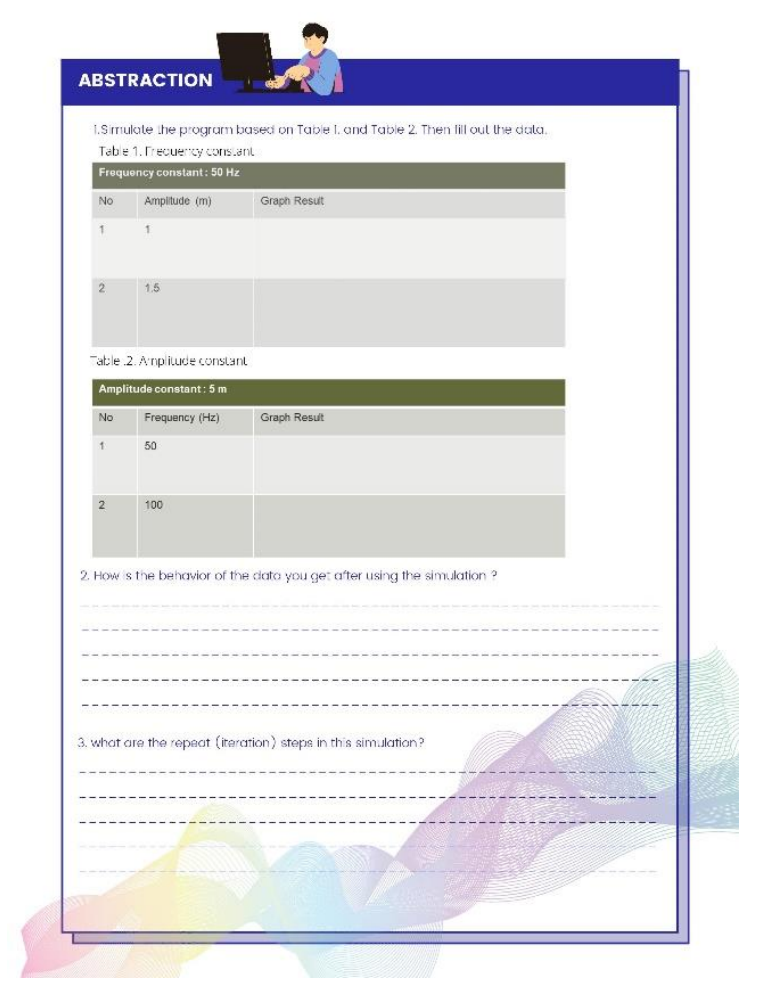

FIGURE 5. The stage of abstraction on worksheet

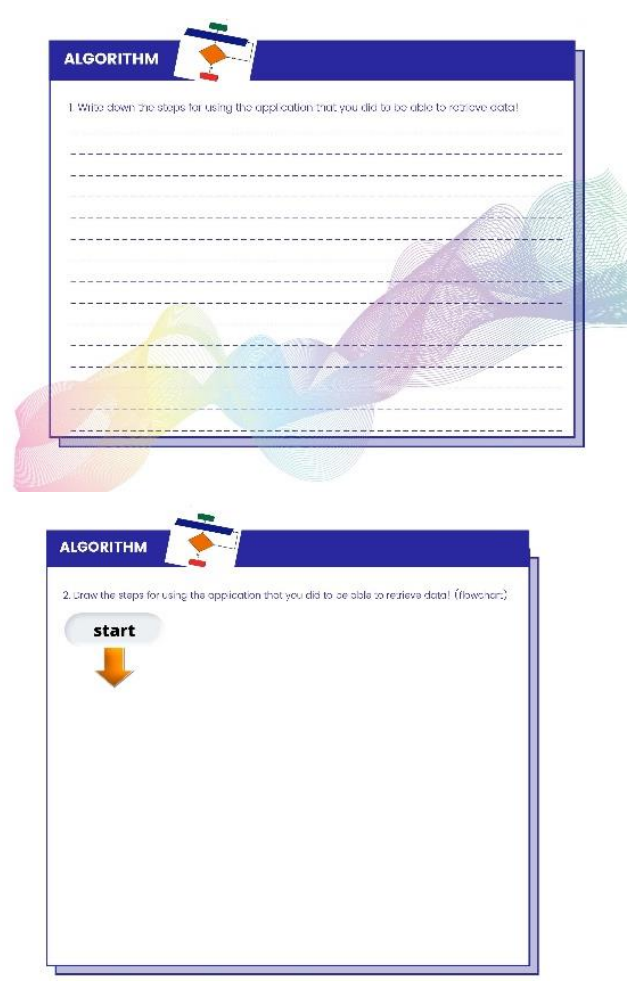

FIGURE 6. The stage of abstraction on worksheet

Abstraction is the stage for practicing CT (Muliyati et al. 2021). This section describes the simulation and processes in the system (FIGURE 5). Abstraction is the process of creating something simple from something complicated (Atmatzidou \& Demetriadis 2016). In this step, students learn about the fundamentals of programming concepts such as sequences and looping (iterations) as part of computing concepts (Lin et al. 2020). This step aims to separate the important from the redundant information, analyze and determine the ordinary behavior or programming structure between different scripts, and identify abstractions. Between different programming environments (Atmatzidou \& Demetriadis 2016). This section also covers data collection, analysis, representation, and problem decomposition. Students are given analysis at the algorithm stage (FIGURE 6), and sets draw a flowchart. Flowcharts are essential in shaping CT and trigger students to understand how computers work (Hsu et al. 2018).

The algorithm in this step is an exercise writing specific and explicit instructions step by step to perform a process (Atmatzidou \& Demetriadis 2016). The algorithm step aims to state algorithm steps explicitly, identify different effective algorithms for a given problem, and find the most efficient algorithm. In this step, students learn about problem-solving skills such as testing and debugging as part of computing practice (Lin et al. 2020).

In the generalization stage (FIGURE 7), students are encouraged to recognize ideas and apply them in other fields; students can interpolate their ideas into the various fields they are involved. This worksheet describes electromagnetic waves, and students can find out for themselves what programs can be developed using the CT framework. Generalization transfers the problem-solving process to various problems, extending the existing solutions in a given situation to cover more cases (Atmatzidou \& Demetriadis 2016). In terms of interrogation, The use of technology is part of a computing perspective. It means students understand the relationship between themselves and others in a technological environment (Lin et al. 2020). 


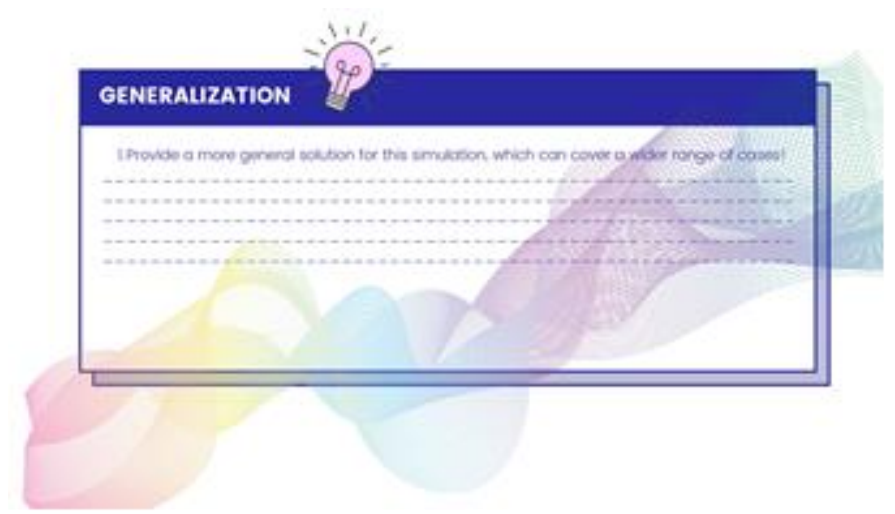

FIGURE 5. The stage of abstraction on worksheet

The final step after the worksheet is complete is to validate it. This is following one part of the development stage. Validation is carried out by colleagues (fellow lecturers) who are experienced in learning materials and media. In studying expert perception, the critical steps in the worksheet for practicing $\mathrm{CT}$, abstraction, algorithmic thinking, and generalization were rated with reasonable interpretation. Meaning this worksheet can allow students to improve their CT skills. A suggestion from a colleague is to add color to the worksheet, so it doesn't look stiff or monotonous (the attached image is a revised worksheet). The revision in the form of changing colors to become more aesthetic turned out to impact students. One of the impacts is to increase students' learning motivation (Alexopoulos 2021).

\section{CONCLUSION}

In this study, a worksheet design from the results of this study has been produced. The resulting worksheets already meet the material and learning media criteria. The writer made improvements by changing the color combination to look more aesthetic. As for the CT skills, the developed worksheets are well integrated. The dimensions of the integrated CT skills are abstraction, algorithm, and generalization. In addition, the resulting worksheets also have six main elements: (1) titles, (2) study guidelines, (3) essential competencies, (4) subject matter or supporting information, (5) tasks or work steps, and (6) student assessment.

\section{REFERENCES}

Alexopoulos, AN, Paolucci, P, Sotiriou, SA et al 2021, 'The colours of the Higgs boson: a study in creativity and science motivation among high-school students in Italy', Smart Learn. Environ, vol. 8 , no. 23.

Atmatzidou, S \& Demetriadis, S 2016, 'Advancing students ' computational thinking skills through educational robotics : A study on age and gender relevant differences', Robotics and Autonomous Systems, vol. 75, pp. 661-670.

Bakri, F, Permana, H, Wulandari, S \& Muliyati, D 2020, 'Student worksheet with ar videos: Physics learning media in laboratory for senior high school students', Journal of Technology and Science Education, vol. 10, no. 2, pp. 231-240.

Bakri, F, Sumardani, D \& Muliyati, D 2019, 'Integrating augmented reality into worksheets: Unveil learning to support higher-order thinking skills', AIP Conference Proceedings, vol. 2169, p. 020012 .

Frigerio, D, Richter, A, Per, E, Pruse, B \& Vohland, K 2021, 'Citizen Science in the Natural Sciences', In: Vohland K. et al. (eds) The Science of Citizen Science, Springer, Cham.

Griffiths, DJ 1999, 'Introduction to electrodynamics (Third ed.)', Prentice Hall, pp. 559-562. 
Gurl, TJ, Fox, R, Dabovic, N \& Leavitt, AE 2016, 'Planning Questions and Persevering in the Practices', National Council of Teachers of Mathematics, The Mathematics Teacher, vol. 110, no. 1, pp. 33-39.

Hsu, T, Chang, S \& Hung, Y 2018, 'How to learn and how to teach computational thinking : Suggestions based on a review of the literature', Computers \& Education, vol. 126, pp. 296-310.

Hussey, T \& Smith, P 2010, 'The uses of learning outcomes', Teaching in Higher Education, vol. 8, no. 3, pp. 357-368.

Jylkkä, J \& Railo, H 2019, 'Consciousness as a concrete physical phenomenon', Consciousness and Cognition, vol. 74, p. 102779.

Khasanah, AN, Sajidan, S \& Widoretno, S 2017, 'Efectiveness of critical thinking indicator-based module in empowering student's learning outcome in respiratory system study material', Jurnal Pendidikan IPA Indonesia, vol. 6, no. 1, pp. 187-195.

Lin, S, Chien, S, Hsiao, C, Hsia, C \& Chao, K 2020, 'Enhancing computational thinking capability of preschool children by game-based smart toys', Electronic Commerce Research and Applications, vol. 44, p. 101011.

Muliyati, D, Sumardani, D, Siswoyo, S, Bakri, F, Permana, H, Handoko, E \& Sari, Ni 2021, 'Development and evaluation of granular simulation for integrating computational thinking into computational physics courses', Education and Information Technologies. pp. 1-28.

Nasrullah, A, Marlina, M \& Dwiyanti, W 2018, 'Development of Student Worksheet-Based College E-Learning Through Edmodo to Maximize the Results of Learning and Motivation in Economic Mathematics Learning', International Journal of Emerging Technologies in Learning (iJET), vol. 13, no. 12, pp. 211-229.

Plevris, V \& Tsiatas, GC 2018, 'Computational Structural Engineering: Past Achievements and Future Challenges', Frontiers in Built Environment, vol. 4, p. 21.

Rufaida, D, Sudarmin, L \& Widiyatmoko, A 2013, 'Development of Microsoft Expression Webassisted IPA LKS', Unnes Science Education Journal (USEJ), vol. 2, no. 1, pp. 209-216.

Russo, J, Hopkins, S 2017, 'Student reflections on learning with challenging tasks: 'I think the worksheets were just for practice, and the challenges were for maths', Math Ed Res J, vol. 29, pp. 283-311.

Tang, X, Yin, Y, Lin, Q, Hadad, R \& Zhai, X 2020, 'Assessing computational thinking: A systematic review of empirical studies’, Computers \& Education, vol. 148, p. 103798.

Trinh-Xuan, D, Bradley, PJ, Brennan, C 2012, 'Fast Fourier Transform Based Iterative Method for Electromagnetic Scattering From 1D Flat Surfaces', IEEE Transactions on Antennas and Propagation, vol. 60, pp. 5464-5467.

Waiyakoon, S, Khlaisang, J \& Koraneekij, P 2015, 'Development of an instructional learning object design model for tablets using game-based learning with scafolding to enhance mathematical concepts for mathematic learning disability students', Procedia - Social and Behavioral Sciences, vol. 174, pp. 1489-1496.

Yulkifi, Y, Ningrum, MV \& Indrasari, W 2019, 'The validity of student worksheet using inquiry based learning model with science process skill approach for physics learning of high school', Jurnal Penelitian \& Pengembangan Pendidikan Fisika, vol. 5, no. 2, pp. 155-162. 


\section{Appendix}

Appendix 1. A CT Skills model applied in the study (Atmatzidou \& Demetriadis 2016)

\begin{tabular}{lll}
\hline CT Step & Defnition & Student skills (The student should be able to) \\
\hline Abstraction & $\begin{array}{l}\text { Create a simple formulation from } \\
\text { something complicated }\end{array}$ & $\begin{array}{l}\text { Separate the importance from the redundant data. } \\
\text { Analyze programming constructions among diferent } \\
\text { programming scripts. }\end{array}$ \\
& $\begin{array}{l}\text { Recognize ideas between diferent software design } \\
\text { environments. }\end{array}$ \\
Algorithm & $\begin{array}{l}\text { Write step-by-step orders for carrying } \\
\text { out a procedure }\end{array}$ & $\begin{array}{l}\text { Classify diferent applied algorithms for a specifed } \\
\text { problem. }\end{array}$ \\
& & $\begin{array}{l}\text { Discover the most efective procedure. } \\
\text { Expand a present solution to cover more possibilities }\end{array}$ \\
\hline \multirow{2}{*}{ Generalization } & $\begin{array}{l}\text { Transfer a problem-solving process to } \\
\text { varied difculties }\end{array}$ & \\
\hline
\end{tabular}

Appendix 2. CT skills and relevant prompts to trigger students' self-refection (Atmatzidou \& Demetriadis 2016)

\begin{tabular}{ll}
\hline CT skills & Type of Question \\
\hline Abstraction & $\begin{array}{l}\text { How would you describe this common behavior? What is the common programming } \\
\text { structure? Which is the information you actually need? What is irrelevant detail and } \\
\text { not necessary in your description? }\end{array}$ \\
Algorithm & $\begin{array}{l}\text { Write step-by-step the operations needed so that you can do what the problem asks. } \\
\text { What are the steps I will need to do to solve this problem? } \\
\text { Peneralization }\end{array}$ \\
\hline
\end{tabular}


